\title{
Nickel-Titanium Alloys Welding of Thin Sheets Using GTAW: Comparative Study Between Similar and Dissimilar Welding with AISI 304 Stainless Steel
}

\author{
Matheus José Cunha de Oliveira ${ }^{a}{ }^{-}$, Raphael Henrique Falcão de Melo ${ }^{b}$, Theóphilo Moura Maciel , \\ Carlos José de Araújo ${ }^{c}$ \\ anstituto Federal de Educação, Ciência e Tecnologia do Ceará - IFCE, campus Sobral, Av. Dr. \\ Guarani, 317, 62040-730, Sobral, CE, Brasil \\ ${ }^{b}$ Instituto Federal de Educação, Ciência e Tecnologia da Paraíba - IFPB, campus Cajazeiras, Eixo da \\ Indústria, Cajazeiras, PB, Brasil \\ ${ }^{c}$ Departamento de Engenharia Mecânica, Universidade Federal de Campina Grande - UFCG, Av. \\ Aprígio Veloso, 882, Bloco BR, 58429-140, Campina Grande, PB, Brasil
}

Received: June 20, 2018; Revised: October 01, 2018; Accepted: October 03, 2018

\begin{abstract}
The objective of the present work was to evaluate welding of thin sheets (thickness $<1 \mathrm{~mm}$ ) of similar and dissimilar NiTi alloys with AISI 304 stainless steel using the Gas Tungsten Arc Welding (GTAW) process and to study the mechanical and metallurgical properties of the joints with and without post-welding heat treatment (PWHT). The GTAW process was chosen because it is more economical than the usual welding processes for NiTi alloys, such as the Laser Beam Welding (LBW). The welded joints were characterized by the techniques of SEM, OM, electrical resistance in temperature (ERT), tensile test and Vickers microhardness. It was observed that the dissimilar joints presented a brittle behavior due to the formation of brittle elements along the weld metal by the excessive increase of the hardness in this region with peaks of hardness higher than $900 \mathrm{HV}$. Similar joints presented superior mechanical behavior, with extensive plastic deformation before rupture and fracture surface with ductile appearance. The PWHT in the similar joints promoted a decrease in the rigidity of the material by minimizing the thermal stresses from the welding process, the PWHT did not influence the dissimilar joints mechanical behavior.
\end{abstract}

Keywords: NiTi, Welding, GTAW, similar joints, dissimilar joints.

\section{Introduction}

Shape Memory Alloys (SMA) are metal alloys for which reversible phase transformations induced by appropriate temperature and/or stress changes are observed. A phase transformation of an SMA is unique, accompanied by high data recovery capacity and stress as a function of temperature changes. Due to its ability to recover its initial strain with a temperature variation, the SMA is intrinsically considered an intelligent material as thermo-mechanical actuators applications ${ }^{1,2}$.

Among the most used materials in this intelligent materials field, the nickel-titanium (NiTi) SMA are well known for its superelasticity properties, shape memory effect, biocompatibility and corrosion resistance when the atomic compositions of nickel and titanium are similar, i.e. close to equiatomic ${ }^{1,3}$. Joining the NiTi SMA is a technological challenge due to the formation of fragile intermetallic compounds, which leads to a marked loss of tenacity from the welded joints, as during solidification cracks associated to the dendritic microstructure of the weld metal are formed. Also, there is still precipitation of deleterious phases in the heat affected zone (HAZ) and the weld metal (WM), resulting in severe

"e-mail: matheus.oliveira@ifce.edu.br. reduction of mechanical resistance ${ }^{4}$. These phenomena are responsible for limiting the applicability of the NiTi SMA in multiple areas of interest.

With the possibility of expanding the field of the NiTi SMA applications, literature reports the joining by welding of this material with other metal alloys to explore the properties of both alloys; a common pair is to weld NiTi with stainless steel ${ }^{5,6}$. Stainless steel has excellent biocompatibility properties, corrosion resistance and are easily welded, specially the austenitic classes, such as the AISI 304. However the dissimilar welding of the NiTi-AISI304 pair results in a brittle structure with undesirable mechanical properties due to the formation of intermetallic elements along the weld metal ${ }^{5,7,8}$. An alternative way to minimize the negative effects of this welding is the use of filler metals ${ }^{9-11}$. Other ways such as promotion of post welding heat treatment (PWHT) can be further explored.

The main joining process used in welding of NiTi SMA is the Laser Beam Welding (LBW), due to its excellent precision and focusing of welding heat, resulting in a shorter HAZ ${ }^{4,5}$. Despite its benefits, the LBW process requires high initial investment to install the necessary infrastructure, which limits its application.

Electric arc welding processes, such as the arc welding process with non-consumable tungsten electrode and 
gas shielding (GTAW), are commonly used in industrial applications and are known to provide high quality welded joints and mechanical strength for most steels, aluminum, copper and their alloys. It would be possible to expect the same behavior for the NiTi alloys. However, according to authors ${ }^{12,13}$ the GTAW welding process negatively affects the mechanical properties of welded NiTi joints due to a large extent HAZ. The presence of contaminants also limited the functional properties of the welded joints. Few papers assessing the mechanical properties of joints welded by the GTAW process have been published ${ }^{14}$.

It is very important to note that most studies on similar and dissimilar welding involving NiTi SMA were performed with wires ${ }^{7-12,15-17}$ and using the LBW process. There are only a few studies on thin sheets ${ }^{18-20}$ and even fewer using simpler and less expensive processes, such as the gas tungsten arc welding (GTAW).

Thus, this work aims to report the possibility of welding similar (NiTi-NiTi) and dissimilar (NiTi-AISI304) joints by the Gas Tungsten Arc Welding (GTAW) process and to evaluate the influence of the realization of post-weld heat treatments in the microstructure and in the mechanical properties, such as hardness, tensile strength and strain variation; and further analyze the fracture surfaces of the joints after welding to understand the main failure mechanism.

\section{Materials and Methods}

For the development of this work, NiTi equiatomic and AISI 304 austenitic stainless steel thin plates (thickness $<1 \mathrm{~mm}$ ) were used. The welding was carried out manually, with no purge gas used to protect the root. It was used the Digiplus A7 from IMC - SOLDAGEM, which is an electronic multiprocess welding power source. The welding parameters were fixed, after previous study, as indicated in Table 1 . The welding speed used was $\mathrm{V}=1.2 \mathrm{~mm} / \mathrm{s}$ (approximate time $=15$ seconds for an $18 \mathrm{~mm}$ bead), diameter of the gas nozzle $=4 \mathrm{~mm}$, electrode diameter $=1 / 16$ inch.

For all welding conditions the filler rod used was the NiTi alloy itself which was taken directly from the thin plates (Figure 1). The post-weld heat treatment (PWHT) on both similar welding (NiTi-NiTi) and dissimilar welding (NiTi-AISI304) consisted of heating the joints at $500^{\circ} \mathrm{C}$ for 120 minutes than furnace cooling, with no controlled atmosphere. This heat treatment was suggested by the NiTi sheet supplier in order to release the thermoelastic

Table 1. Welding conditions

\begin{tabular}{lcccc}
\hline Joint & $\begin{array}{c}\text { Current } \\
\text { nature }\end{array}$ & $\begin{array}{c}\text { Welding } \\
\text { current (A) }\end{array}$ & $\begin{array}{c}\text { Ar flux } \\
(1 / \text { min })\end{array}$ & PWHT \\
\hline Similar S11 & DCEN & $\sim 25$ & 12 & No \\
Similar S12 & DCEN & $\sim 25$ & 12 & Yes \\
Dissimilar D11 & DCEN & $\sim 25$ & 12 & No \\
Dissimilar D12 & DCEN & $\sim 25$ & 12 & Yes \\
\hline
\end{tabular}

martensitic transformation. Joints were evaluated by electrical resistance in temperature (ERT), Vickers microhardness test, optical microscopy (OM), tensile test and scanning electron microscopy (SEM).

In order to determine the phase transformation temperatures the evaluation of the electrical resistance variation temperature (ERT) an average rate of $4^{\circ} \mathrm{C} / \mathrm{min}$, for a temperature range from $-60^{\circ} \mathrm{C}$ to $100^{\circ} \mathrm{C}$ was used. The test consists of heating the joints to the reference austenitic state (at $100^{\circ} \mathrm{C}$ ), cooling it to $-60^{\circ} \mathrm{C}$ and then heating it to the reference state again ${ }^{21}$, illustrated at Figure 2. The electrical resistance variation measurements were performed according to the scheme of Figure 3. This technique was chosen in detriment of the Differential Scanning Calorimetry (DSC) as it is a nondestructive technique for the determination of the phase transformation temperatures which were calculated from the tangent method ${ }^{22}$. The intersection of the tangent lines

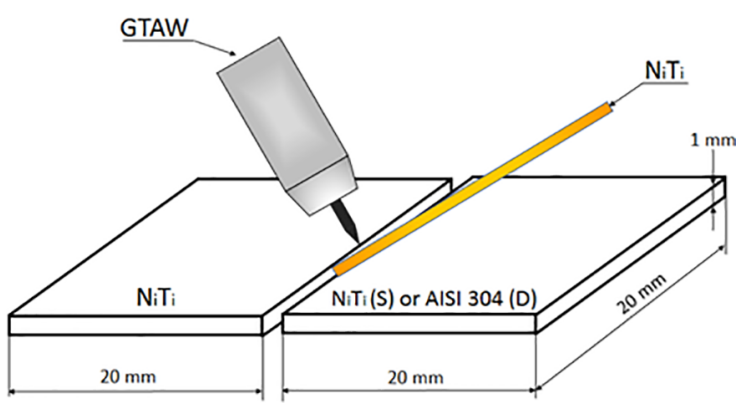

Figure 1. Schematic representation of joints welding.

\section{Reference state (Austenitic)}

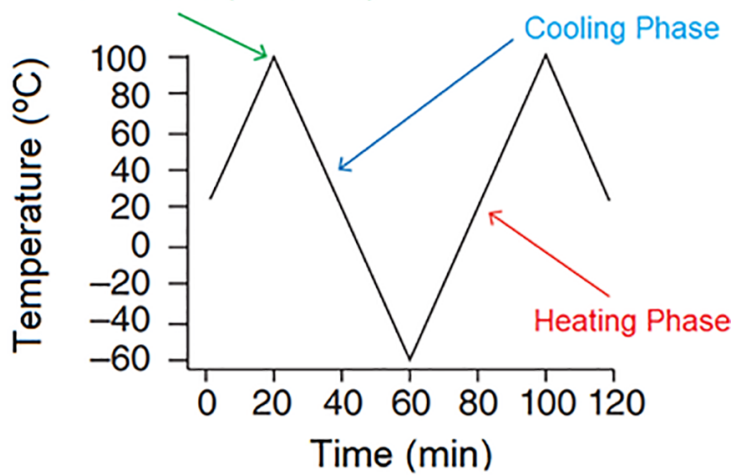

Figure 2. Thermal cooling and heating cycle in the ERT test.

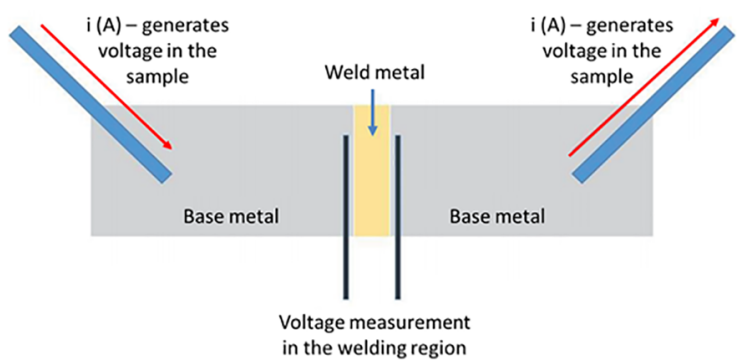

Figure 3. Schematic diagram of the voltage measurement for the welding region electrical resistance determination. 
denotes the temperature at which the phase transformation occurs $^{2,23}$.

Joints microstructure was analyzed using metallurgical microscope Olympus, BX-51 model. A hydrochloric acid, nitric acid and hydrofluoric acid mixture was prepared for microstructure revelation. In the Vickers microhardness (HV) tests the welded joints were tested by applying a load of 50 grams-force (gf) for 15 seconds for the similar joints and a load of 300 grams-force (gf) for 15 seconds for the dissimilar joints, due to the greater hardness presented for these. The equipment used for the test was a Future Tech microindentator, model FM-700. The spacing between the impressions was roughly $0.2 \mathrm{~mm}$, passing through the weld entire length starting from one side of the base metal until it crosses the weld metal and reaches the other base metal side. For the tensile test, the standard ASTM F2516-14 was used (Figure 4). The fracture surface was analyzed using a scanning electron microscope (SEM) of the TESCAN brand, model VEGA $3 \mathrm{SBH}$.

\section{Results and Discussion}

In Figure 5-a is presented the percentage variation curves of the electrical resistance in temperature (ERT) for the NiTi base metal, as received (AR), prior to the PWHT

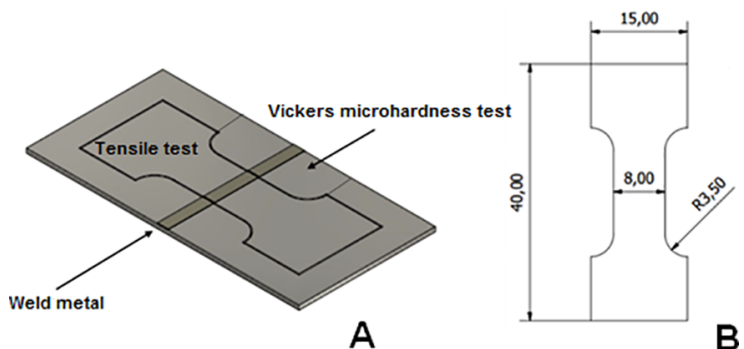

Figure 4. Schematic representation of (a) tensile test and microhardness test samples (b) tensile test sample dimensions, in $\mathrm{mm}$.
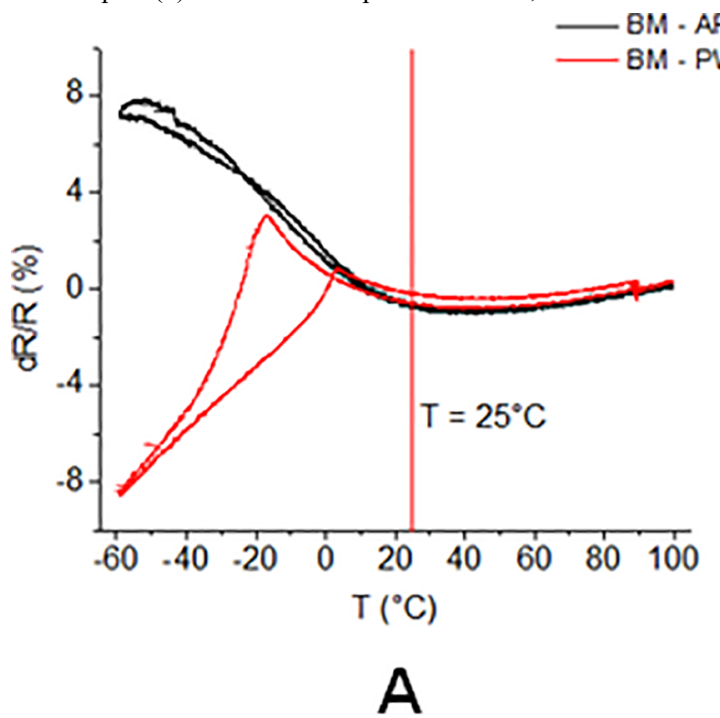

and after PWHT. In Figure 5-b is presented the NiTi similar joints, $\mathrm{S} 11$ and S12, taking the temperature of $100^{\circ} \mathrm{C}$ as the reference state for the calculation of electrical resistance variation. The start and end temperatures of transformation were determined from the intersection of the tangent lines.

It can be inferred that there is the direct martensitic transformation during the cooling phase, whereas the reverse martensitic transformation is observable in the heating phase. The ERT curves especially that of the base metal (NiTi sheet without weld), are typical of the two-stage martensitic transformation of NiTi SMA, austenite, cubic structure, to the rhombohedral $\mathrm{R}$ phase with great distortion at $\alpha$ angle, and finally to the monoclinic martensite, forming a peak in the cooling phase that begins at Rs temperature ${ }^{2,24}$. The S11 joint was submitted to a welding thermal cycle and this acted as a PWHT. The S12 joint was also submitted to a welding thermal cycle although in addition it was further heat treated by the real PWHT. These heating cycles promoted the aging of the microstructure and causing a second type of martensite to precipitate in the material which is characterized by the largest peak decrease in Figure 5-b.

According to Table 2 it is still possible to observe a slight increase in the martensitic transformation start temperature (Rs) when welding these alloys by the GTAW process. Joint $\mathrm{S} 12$ presented an increase of about $4^{\circ} \mathrm{C}$ relative to joint $\mathrm{S} 11$ and increase of $8^{\circ} \mathrm{C}$ relative to the base metal (reference). These increases probably occur due to the impoverishment of nickel in the NiTi matrix one since $\mathrm{Ni}_{4} \mathrm{Ti}_{3}$ precipitation can occur, causing an increase in the phase transformation temperatures ${ }^{12}$.

Vickers microhardness profile of the evaluated joints is shown in Figure 6. The $0 \mathrm{~mm}$ mark was considered the center of the weld metal. The weld metal had dimensions of approximately $4 \mathrm{~mm}$. The positive values of distance are directed to the base metal AISI 304 (for the dissimilar joints), 
Table 2. R phase starting temperature

\begin{tabular}{lcc}
\hline \multirow{2}{*}{ Condition } & \multicolumn{2}{c}{ Rs } \\
\cline { 2 - 3 } & $\boldsymbol{\mu}\left({ }^{\circ} \mathbf{C}\right)$ & $\boldsymbol{\sigma}\left({ }^{\circ} \mathbf{C}\right)$ \\
\hline Base Metal - AR & $-13,7$ & 0,22 \\
Base Metal - & 18,12 & 0,12 \\
PWHT & 22,10 & 0,31 \\
S11 & 26,61 & 0,26 \\
S12 & & \\
\hline
\end{tabular}

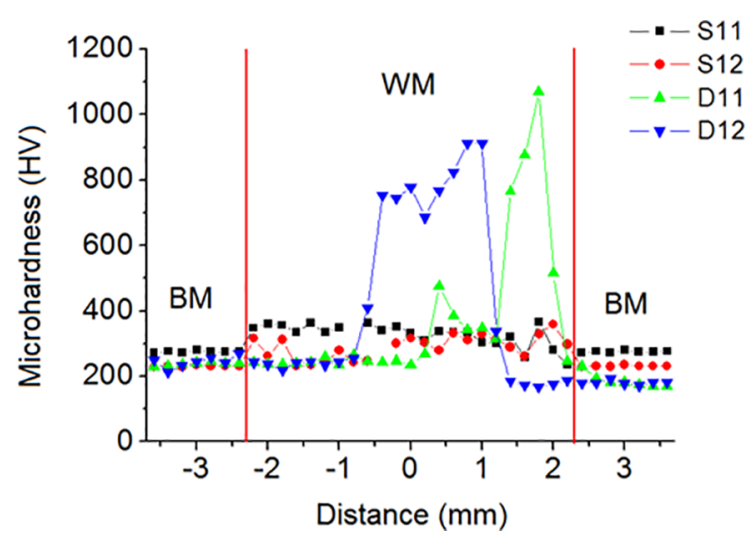

Figure 6. Microhardness profile of the welded joints, the AISI 304 base metal is located at the right side for the dissimilar joints.

whereas the negatives to the base metal NiTi. It was noticed that it was not possible to determine the extent of the heat affected zone (HAZ).

This microhardness profile observed in Figure 6 for NiTi similar joints (S11 and S12) exhibited a more homogeneous microhardness profile, presenting small increase of hardness in the possible HAZ and towards the weld metal, mainly when contrasted to the behavior observed in the dissimilar joints (D11 and D12).

The S12 (430 $\pm 68 \mathrm{HV})$ welding condition presented higher hardness than the S11 $(353 \pm 45 \mathrm{HV})$ welding condition because it was subjected to PWHT, the hardness increases observed after the PWHT is linked to phase precipitation such as $\mathrm{Ni}_{3} \mathrm{Ti}_{4}{ }^{25}$. It can be stated that the qualitative microhardness profile is identical to those reported by ${ }^{12,26-28}$. There was no partially diluted zone in the similar joints, so there was no such great increase in microhardness at the weld interface, as can be observed in Figure 7 for the S12 joint. Also, it is possible to observe the competitive grain growth resulting in a coarse microstructure of columnar grains. Columnar grain size is a function of the original base metal grain size, welding energy and joint geometry, thus impacting on the joint mechanical behavior ${ }^{29}$. Furthermore, it can be stated that the PWHT do not result directly on weld metal grain refine, with the possibility to degrade this properties due to phase formations.

For the dissimilar joints it was possible to note a considerably hardness increase in the weld metal (WM) region, decreasing towards both base metals, to the two sides of the joints, reaching expected values of HV hardness for both base metals, i.e. around $220 \mathrm{HV}$ for NiTi and 170 HV for AISI 304.

Also, the existence of high hardness peaks, 800-1100 HV, for joints D11 and D12 were mainly concentrated towards the weld metal region. These are related to the intermetallic formation during welding, due to the large number of different alloying elements present in the steel matrix ( $\mathrm{Cr}$ and $\mathrm{Ni}$ ) in addition to $\mathrm{Fe}$ and $\mathrm{C}$, and also nickel and titanium for the NiTi SMA ${ }^{9,19}$. The heat treatment used was not effective in the minimization and appearance of these peaks. Those elements lead to the presence of a partially diluted zone (PDZ), as can be seen on Figure 8.

The qualitative behavior of the hardness profiles observed in Figure 6 was also reported in the literature ${ }^{8,17}$. The authors reported that high hardness peaks (800-1400 $\mathrm{HV}$ ) were observed in the melt zone extension of the NiTiAISI304 dissimilar joint, associated with the precipitation of intermetallic as $\mathrm{TiFe}_{2}, \mathrm{FeTi}, \mathrm{TiCr}_{2}, \mathrm{TiC}, \mathrm{TiNi}_{3}$.

EDS analyzes in the $\mathrm{PDZ}$ region (D11 joint) is presented in Figure 9. The spectrum 1 is located at the AISI304 base metal side, the spectrum 2 is located at the PDZ and the spectrum 3 is located at the edge of the partial diluted zone, in the WM (Figure 9). Chemical composition reported by spectrum 1 indicated that only Mn (1.63\%wt), Ni (7.89\%wt), $\mathrm{Cr}(19.64 \% \mathrm{wt})$ and $\mathrm{Fe}(70.84 \% \mathrm{wt})$ are presented, mainly AISI 304 chemical composition. The spectrum 2 indicated that in the partial diluted zone nickel (16.13\%wt) and titanium (26.45\%wt) are also presented. Iron and chromium are presented in $44.11 \%$ wt and $12.51 \%$ wt. Finally, the spectrum 3 indicated that in the weld metal, Ni (49.30\%wt) and $\mathrm{Ti}$ (37.28\%wt) are the majority, $\mathrm{Fe}(11.51 \% \mathrm{wt})$ and $\mathrm{Cr}(1.92$ $\% \mathrm{wt})$, the minority. This chemical composition variation is the mainly variable responsible for the PDZ formation and the microhardness behavior previously discussed.

What is observed in Figure 10 is that the dissimilar joints ruptured prematurely when reaching UTS of $100 \mathrm{MPa}$, with final deformation inferior than $0.5 \%$. NiTi-AISI304 joints' UTS values are close to those found in studies in the literature,

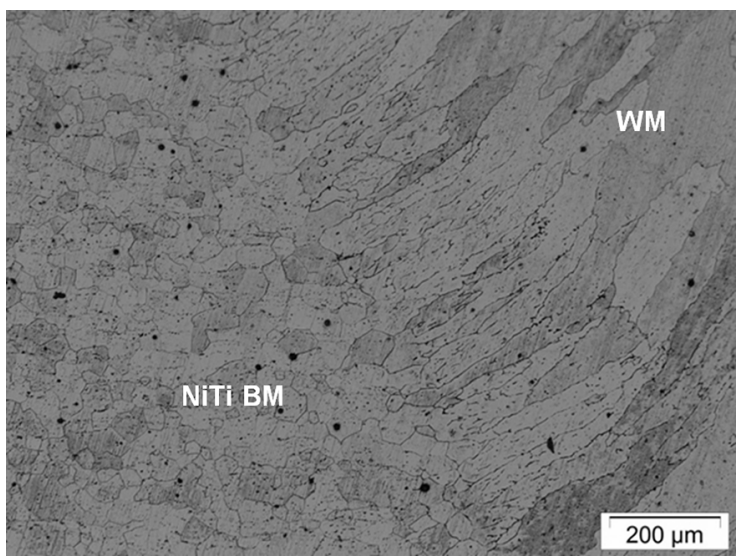

Figure 7. S12 joint microstructure observed through OM, interface between $\mathrm{BM}$ and WM. 

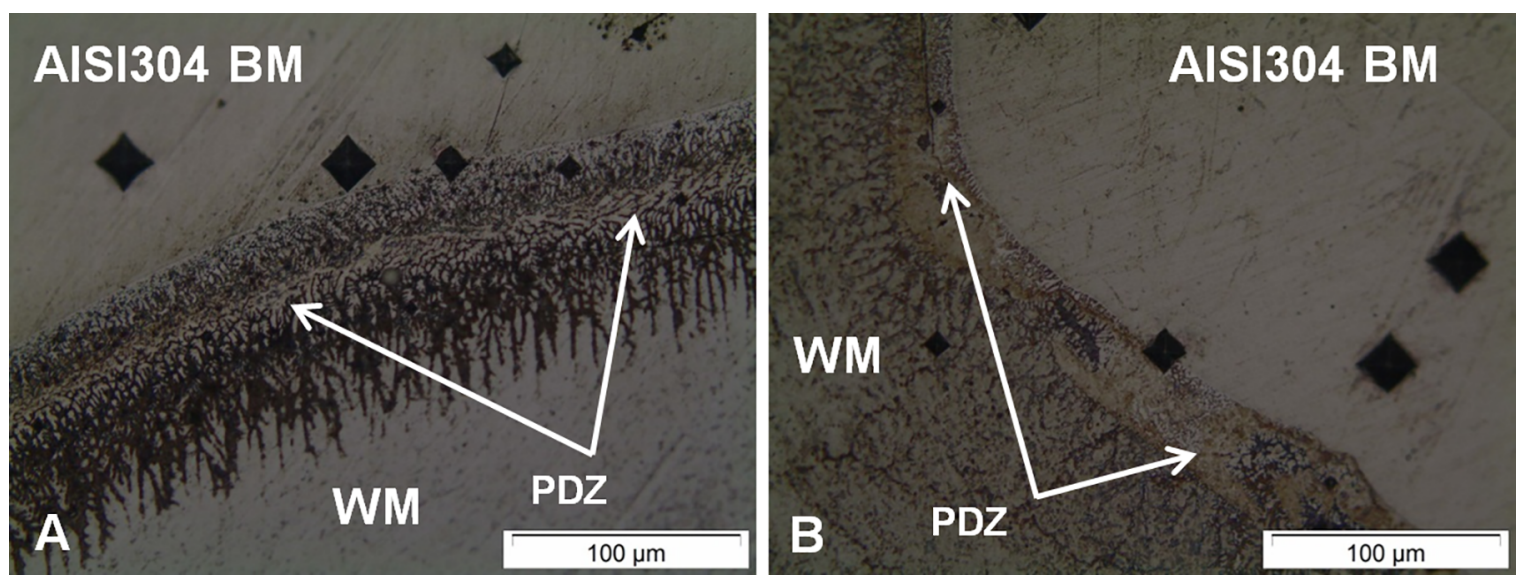

Figure 8. Partial diluted zones (a) D11 (b) D12.
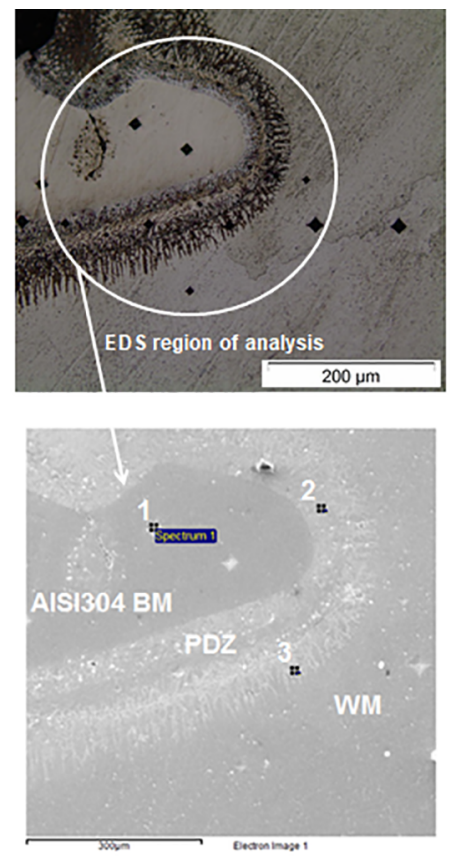

\begin{tabular}{c|c|c|c}
\hline Element & wt.\%1 & wt.\% 2 & wt.\%3 \\
\hline $\mathrm{Cr}$ & 19.64 & 12.51 & 1.92 \\
\hline $\mathrm{Mn}$ & 1.63 & 0.79 & 0.00 \\
\hline $\mathrm{Fe}$ & 70.84 & 44.11 & 11.51 \\
\hline $\mathrm{Ni}$ & 7.89 & 16.13 & 49.30 \\
\hline $\mathrm{Ti}$ & 0.00 & 26.45 & 37.28 \\
\hline
\end{tabular}

Figure 9. EDS analysis of the D11 dissimilar joint.

as $(\mathrm{UTS}=134 \mathrm{MPa}){ }^{11}$ and $(\mathrm{UTS} \sim 200 \mathrm{MPa}){ }^{8}$ for welding using the LBW process. This behavior is directly related to the observation of regions of high hardness in the weld metal. During the plastic deformation the dislocations are accumulated in the regions of high tension and have their restricted mobility which culminates with the premature fracture. One reported approach for minimizing the negative effects of such difficulties in welding is the use of metallic interlayers between dissimilar metals. The use of these layers aims to mitigate these effects and to promote desirable

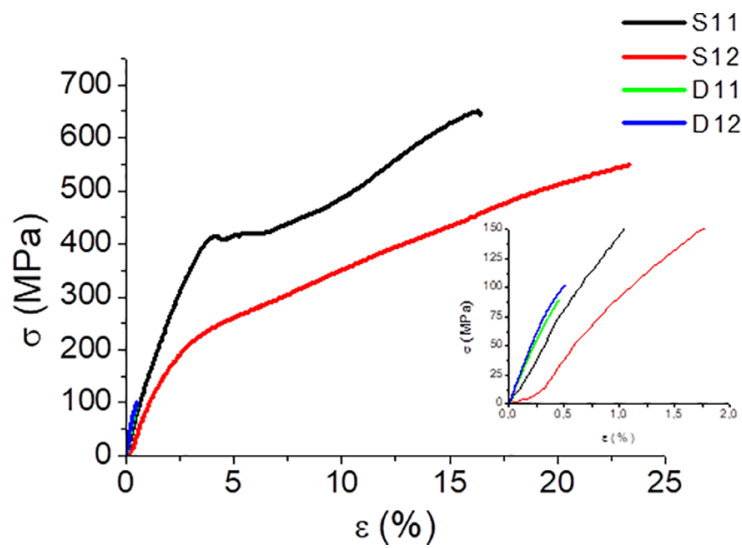

Figure 10. Stress vs. Strain behavior of the welded joints.

mechanical properties for the dissimilar NiTi-stainless steel joints ${ }^{9-11}$. The use of intermetallic layers is a viable approach for obtaining NiTi-stainless steel joints welded by the laser beam welding (LBW) process due to its precise control. Other approaches, such as performing a post-weld heat treatment, may be further explored.

Distinct behavior is presented by the similar joints that presented an extensive area of plastic deformation before failing, reaching UTS of $\sim 650 \mathrm{MPa}$ and elongation of $16 \%$ to the condition without heat treatment and $\sim 550 \mathrm{MPa}$ and elongation of $23 \%$ to the thermally treated joint, mechanical behavior comparable to the NiTi base metal used (UTS of $750 \mathrm{MPa}$ and elongation of $21 \%$ ). It is also possible to observe that the heat treatment of the S12 joint promoted a decrease in the rigidity of the material by minimizing the thermal stresses from the welding process. This also promoted a final deformation increase. Therefore the PWHT could be a viable tool to manage the NiTi-NiTi rigidity and enhance its ductility.

This mechanical behavior result for similar NiTi joints can be compared with those reported in the literature: Melo et al. ${ }^{22}$ using factorial experiment were able to achieve NiTi-NiTi welded joints by laser with UTS of $682 \mathrm{MPa}$ 

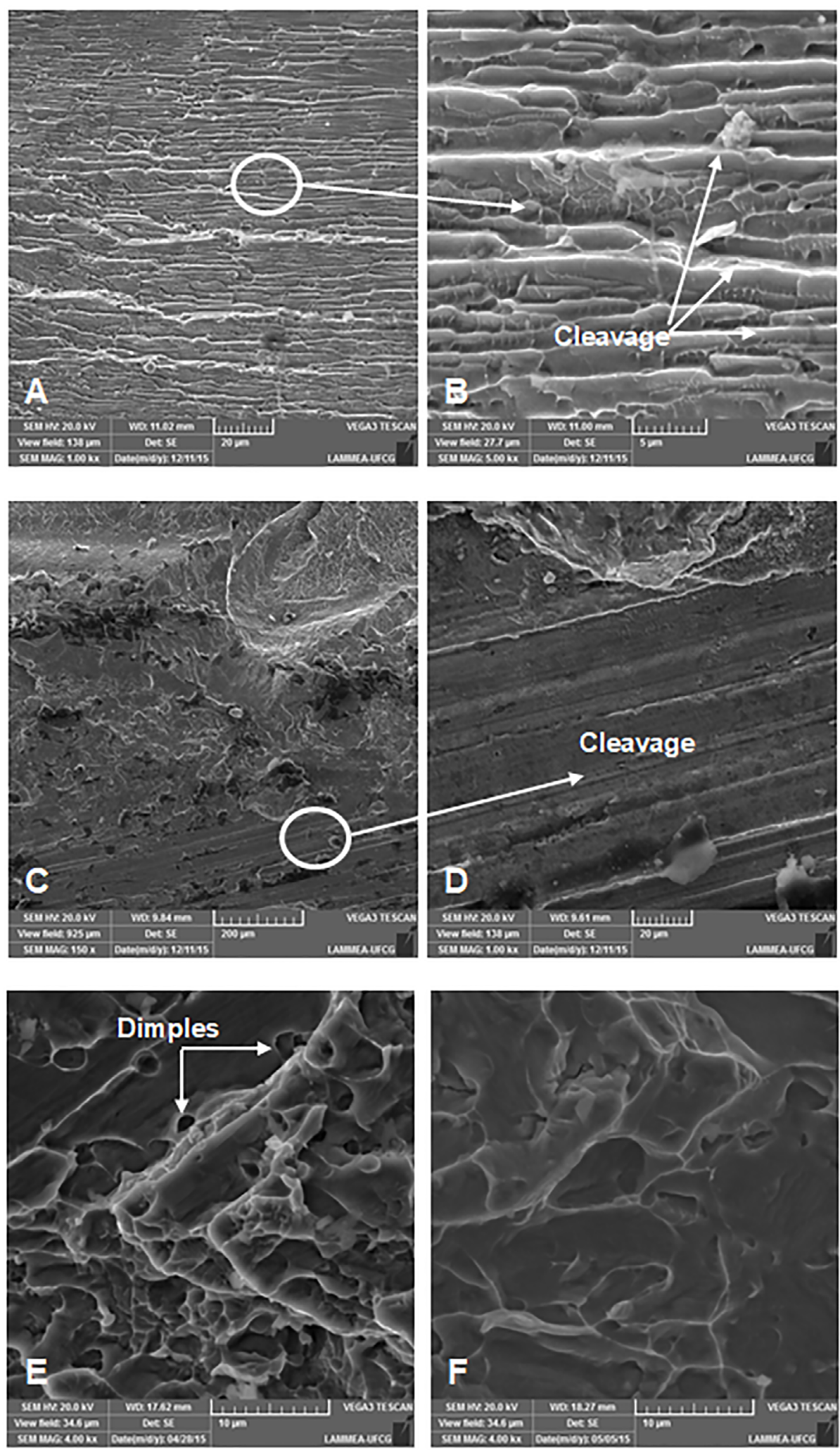

Figure 11. SEM images of the fracture surfaces $(a, b)$ D11; $(c, d) D 12 ; e-S 11$ and $\mathrm{f}-\mathrm{S} 12$. 
and elongation of $12.7 \%$, Wang et al. ${ }^{30}$ welding NiTi thin sheets obtained UTS of $450 \mathrm{MPa}$ and elongation of $5.1 \%$ using the LBW process, Mirshekari et al. ${ }^{8}$ achieved UTS of $835 \mathrm{MPa}$ using the LBW and NiTi wires and Gugel et al ${ }^{17}$ achieved a NiTi welded joint UTS of about $70 \%$ of its corresponding base metal. Thus, it is also possible to reach satisfactory mechanical behavior of NiTi-NiTi joints using the GTAW process.

Most recently, Oliveira et al. ${ }^{14}$ presented a comparison of the different joining techniques for the NiTi shape memory alloys. For the NiTi similar welding mostly problems are related to formation of brittle intermetallics, compositional variations and precipitation. LBW is the most studied process for the NiTi welding due to minimal thermal effect on the joint. For the NiTi dissimilar welding the authors state that there is still limited research on this topic.

Figure 11 (a-f) present the SEM images of the fracture regions for the dissimilar joints D11 (a-b) and D12 (c-d), and similar joints (e-f). Joints D11 and D12 have failed at the interface between the weld metal and the base metal. This characteristic is common for welded joints that fail due to brittle fracture, usually due to the presence of welding defects and/or the formation of intermetallic compounds precipitated in this region, as evidenced by the observed microhardness profile. It is possible to notice that the main mechanism of fracture was ductile, with the presence of dimples in the similar joints, S11 and S12. In addition, the presence of parabolic dimples (Figure 11-f) was observed when submitted to PWHT, whereas in the non-PWHT condition, dimples of smaller size were observed (Figure 11-e).

In the dissimilar joints, the micro aspect of these surfaces indicates that the mechanism of fracture was predominantly by cleavage. It is possible to observe planes of different heights along the fracture surfaces, characterizing the type of fragile fracture ${ }^{8}$. This fracture is fragile and of transgranular origin, since fracture cracks pass through the grains, presenting a faceted texture, as a result of changes in orientation of the cleavage planes from one grain to another. Most intermetallics lead to brittle fracture, with little crack tolerance. The complex structures of these compounds have large Burgers vectors, thus requiring less energy for fracture than for displacement during deformation.

\section{Conclusion}

In this work a comparative study was performed on the mechanical behavior of similar and dissimilar nickel-titanium joints welded by the micro GTAW process and evaluating the influence of post-weld heat treatment on these properties. It was possible to achieve good appearance weld beads with no oxidation or porosity. The Vickers microhardness test allowed the identification of high hardness peaks of the order of $1000 \mathrm{HV}$ in the weld metal for the dissimilar joints due to the formation of fragile intermetallic in this region. A slightly hardness increase was observed in the HAZ and WM of the similar joints. It was possible to notice that the dissimilar welded joints failed under UTS of $100 \mathrm{MPa}$ exhibiting brittle fracture profile, by cleavage. Similar welded joints exhibited distinct mechanical behavior with extensive plastic deformation prior to failure. The post-weld heat treatment in the similar joints promoted a decrease in the rigidity of the material by promoting the relief of thermal stresses from the welding process. It was possible to achieve satisfactory mechanical behavior with similar NiTi welded joints using the GTAW process.

\section{References}

1. Lagoudas DC, ed. Shape Memory Alloys: Modeling and Engineering Applications. New York: Springer US; 2008.

2. Otsuka K, Wayman CM, eds. Shape Memory Materials. Cambridge: Cambridge University Press; 1998.

3. Jani JM, Leary M, Subic A, Gibson MA. A review of shape memory alloy research, applications and opportunities. Materials \& Design (1980-2015). 2014;56:1078-1113.

4. Akselsen OM. Joining of Shape Memory Alloys In: Cismasiu C, ed. Shape Memory Alloys. Rijeka: Sciyo; 2010.

5. Rao A, Srinivasa AR, Reddy JN. Design of Shape Memory Alloys (SMA) Actuators. Cham: Springer; 2015.

6. Brandal G, Satoh G, Yao YL, Naveed S. Beneficial Interface Geometry for Laser Joining of NiTi to Stainless Steel Wires. Journal of Manufacturing Science and Engineering. 2013;135(6):061006

7. Vannod J, Bornert M, Bidaux JE, Bataillard L, Karimi A, Drezet $\mathrm{JM}$, et al. Mechanical and microstructural integrity of nickeltitanium and stainless steel laser joined wires. Acta Materialia. 2011;59(17):6538-6546.

8. Mirshekari GR, Saatchi A, Kermanpur A, Sandrnezhaad SK Laser welding of NiTi shape memory alloy: Comparison of the similar and dissimilar joints to AISI 304 stainless steel. Optics \& Laser Technology. 2013;54:151-158.

9. Li H, Sun D, Gu X, Dong P, Lv Z. Effects of the thickness of $\mathrm{Cu}$ filler metal on the microstructure and properties of laserwelded TiNi alloy and stainless steel joint. Materials \& Design. 2013;50:342-350.

10. Li HM, Sun DQ, Cai XL, Dong P, Wang WQ. Laser welding of TiNi shape memory alloy and stainless steel using Ni interlayer. Materials \& Design. 2012;39:285-293.

11. $\mathrm{Ng} \mathrm{CH}$, Mok SHE, Man HC. Effect of Ta interlayer on laser welding of NiTi to AISI 316L stainless steel. Journal of Materials Processing Technology. 2015;226:69-77.

12. Falvo A, Furgiuele FM, Maletta C. Laser welding of a NiTi alloy: Mechanical and shape memory behavior. Materials Science and Engineering: A. 2005;412(1-2):235-240.

13. Gong WH, Chen YH, Li LM. Microstructure and properties of micro welded joint of TiNi shape memory alloy. Transactions of Nonferrous Metals Society of China. 2011;21(9):2044-2048. 
14. Oliveira JP, Miranda RM, Braz Fernandes FM. Welding and Joining of NiTi Shape Memory Alloys: A Review. Progress in Materials Science. 2017;88:412-466.

15. Zeng Z, Yang M, Oliveira JP, Song D, Peng B. Laser welding of NiTi shape memory alloy wires and tubes for multi-functional design applications. Smart Materials and Structures. 2016;25(8):085001.

16. Burdet P, Vannod J, Hessler-Wyser A, Rappaz M, Cantoni M. Three-dimensional chemical analysis of laser-welded NiTistainless steel wires using a dual-beam FIB. Acta Materialia. 2013;61(8):3090-3098.

17. Gugel H, Schuermann A, Theisen W. Laser welding of NiTi wires. Materials Science and Engineering: A. 2008;481-482:668-671.

18. Pouquet J, Miranda RM, Quintino L, Williams S. Dissimilar laser welding of NiTi to stainless steel. International Journal of Advanced Manufacturing Technology. 2012;61(1-4):205-212.

19. Gugel H, Theisen W. Microstructural investigations of laser welded dissimilar Nickel-Titanium-steel joints. ESOMAT 2009. 2009;05009.

20. Qiu XM, Sun CD, Li MG, Liu WH. Microstructures and properties of welded joint of TiNi shape memory alloy and stainless steel. China Welding (English Edition). 2004;14(3):475-479.

21. Reis RPB, de Araújo CJ, Silva LAR, Queiroga SLM. Desenvolvimento de um sistema de medição da variação de resistência elétrica em função da temperatura: aplicação a caracterização de ligas com memória de forma. In: IV Congresso Nacional de Engenharia Mecânica (IV CONEM); 2006 Aug 22-25; Recife, PE, Brazil.

22. de Melo RHF, de Lima MSF, de Oliveira MJC, Maciel TM, de Araújo CJ. Estudo de juntas soldadas a laser de chapas finas de liga com memória de forma NiTi austenítica. Revista Brasileira de Aplicações de Vácuo. 2017;36(2):89-101.
23. Airoldi G, Lodi DA, Pozzi, M. The Electrical Resistance of Shape Memory Alloys in the Pseudoelastic Regime. Journal de Physique IV. 1997;7(C5):507-512.

24. Lukáš P, Šittner P, Lugovoy D, Neov D, Ceretti M. In situ neutron diffraction studies of the R-phase transformation in the NiTi shape memory alloy. Applied Physics A. 2002;74(Suppl. 1):S1121-S1123.

25. Chan CW, Man HC. Reduction of environmentally induced cracking of laser-welded shape memory NiTi wires via postweld heat-treatment. Materials Science and Engineering: A. 2013;588:388-394.

26. Yang D, Jiang HC, Zhao MJ, Rong LJ. Effect of post-weld annealing on microstructure and properties of NiTi welding joints. Materials Research Innovations. 2014;18(Suppl. 4):588591.

27. Tuissi A, Besseghini S, Ranucci T, Squatrito F, Pozzi M. Effect of Nd:YAG laser welding on the functional properties of the Ni-49.6 at.\%Ti. Materials Science and Engineering: $A$. 1999;273-275:813-817.

28. Hsu YT, Wang YR, Wu SK, Chen C. Effect of CO2 laser welding on the shape-memory and corrosion characteristics of TiNi alloys. Metallurgical and Materials Transactions A. 2011;32(3):569-576.

29. American Welding Society. Welding Handbook Volume 2: Welding Processes - Part 1. Miami: American Welding Society; 2015.

30. Wang W, Yang X, Li H, Cong F, Liu Y. Effect of Laser Welding Parameters on Formation of NiTi Shape Memory Alloys Welds. Advances in Materials Science and Engineering. 2014;2014:494851. 